\title{
Universiteit
}

Leiden

The Netherlands

\section{Risk of Coronary Heart Disease and Mortality for Adults With Subclinical Hypothyroidism Reply}

Rodondi, N.; Bauer, D.C.; Gussekloo, J.

\section{Citation}

Rodondi, N., Bauer, D. C., \& Gussekloo, J. (2010). Risk of Coronary Heart Disease and Mortality for Adults With Subclinical Hypothyroidism Reply. Journal Of The American Medical Association, 304(22), 2482-2482. doi:10.1001/jama.2010.1788

Version: $\quad$ Not Applicable (or Unknown)

License: $\quad$ Leiden University Non-exclusive license

Downloaded from: https://hdl.handle.net/1887/117637

Note: To cite this publication please use the final published version (if applicable). 


\section{Risk of Coronary Heart Disease and Mortality for Adults With Subclinical Hypothyroidism}

To the Editor: In their study, Dr Rodondi and colleagues ${ }^{1}$ addressed the issue of the relationship between subclinical hypothyroidism and coronary heart disease (CHD) or mortality. Previous large prospective cohort studies have provided conflicting results about this extensively studied association. In the study by Rodondi et al, an attempt to reduce the effects of several confounders (including age, sex, degree of thyroid stimulating hormone [TSH] elevation, and pre-existing cardiovascular disease) was performed. ${ }^{1}$ However, the finding of no association of risk with subclinical hypothyroidism for TSH concentration up to $10.0 \mathrm{mIU} / \mathrm{L}$ may be flawed because it did not provide information about the body mass index (BMI) of the patients diagnosed with subclinical hypothyroidism.

This might be a problem because subclinical hypothyroidism, especially when characterized by minor increases in serum TSH levels, is frequently observed among obese patients. ${ }^{2-4}$ The elevated serum TSH found in obese (and particularly in morbidly obese) patients may be a mere consequence of the excess body weight rather than a condition of primary thyroid failure..$^{2-4}$ This concept would imply that obese patients with a moderate elevation in serum TSH would not experience increased systemic vascular resistance, altered endothelial function, increased atherosclerosis, altered coagulability, and lipid abnormalities, which account for the increased risk of CHD associated with subclinical hypothyroidism. ${ }^{5}$

Positive tests for thyroid autoantibodies are the only parameters able to discriminate between true subclinical hypothyroidism and obesity-induced hyperthyrotropinemia. ${ }^{3}$ Because thyroid antibodies were not taken into account in diagnosing subclinical hypothyroidism in the study by Rodondi et al, the conclusions may have been biased. Indeed, obese patients with a moderately increased TSH (up to $10 \mathrm{mIU} / \mathrm{L}$ ) may include a subgroup of patients who are not truly hypothyroid, thus underestimating the real CHD risk associations of subclinical hypothyroidism (defined as high serum level of TSH with normal free thyroxine levels and positive test results for thyroid antibodies).

\author{
Mario Rotondi, MD, PhD \\ Flavia Magri, MD, PhD \\ Luca Chiovato, MD, PhD \\ luca.chiovato@fsm.it \\ Unit of Internal Medicine and Endocrinology \\ Fondazione Salvatore Maugeri IRCCS \\ Pavia, Italy
}

Financial Disclosures: None reported.
1. Rodondi N, den Elzen WP, Bauer DC, et al; Thyroid Studies Collaboration. Subclinical hypothyroidism and the risk of coronary heart disease and mortality. JAMA. 2010;304(12):1365-1374.

2. Reinehr T, de Sousa G, Andler W. Hyperthyrotropinemia in obese children is reversible after weight loss and is not related to lipids. I Clin Endocrinol Metab. 2006;91(8):3088-3091.

3. Rotondi M, Leporati P, La Manna A, et al. Raised serum TSH levels in patients with morbid obesity: is it enough to diagnose subclinical hypothyroidism? Eur J Endocrinol. 2009;160(3):403-408.

4. Reinehr T. Obesity and thyroid function. Mol Cell Endocrinol. 2010;316 (2):165-171.

5. Biondi B, Cooper DS. The clinical significance of subclinical thyroid dysfunction. Endocr Rev. 2008;29(1):76-131.

To the Editor: Dr Rodondi and colleagues ${ }^{1}$ assessed the risk of CHD and total mortality for adults with subclinical hypothyroidism. In this study, the hazard ratio (HR) for CHD events was 1.00 (95\% confidence interval [CI], 0.86-1.18) for a TSH level of 4.5 to $6.9 \mathrm{mIU} / \mathrm{L}, 1.17$ (95\% CI, 0.96-1.43) for a TSH level of 7.0 to $9.9 \mathrm{mIU} / \mathrm{L}$, and 1.89 (95\% CI, 1.28-2.80) for a TSH level of 10.0 to 19.9 mIU/L. They concluded that subclinical hypothyroidism was associated with an increased risk of CHD events and CHD mortality in persons with higher TSH levels, particularly in those with a TSH concentration of $10 \mathrm{mIU} / \mathrm{L}$ or greater, and that minimal TSH elevations were not associated with an increased risk of CHD events and CHD mortality. However, they did not verify the CHD events and CHD mortality among those within the reference range of TSH levels.

TSH levels within the reference range may be positively associated with $\mathrm{BMI}^{2}$ and inversely associated with insulin sensitivity. ${ }^{3}$ We investigated the relationship between thyroid function and carotid intima-media thickness (CIMT) in 643 participants with euthyroid status and demonstrated that CIMT was independently associated with thyroid function within the normal reference range, which suggests increased cardiovascular risk in persons with lownormal thyroid function. ${ }^{4}$ Furthermore, in a populationbased prospective cohort study, TSH levels even within the reference range were positively and linearly associated with CHD mortality in women. ${ }^{5}$

GUIDELINES FOR LETTERS. Letters discussing a recent JAMA article will have the best chance of acceptance if they are received within 4 weeks of the article's publication date. Letters may have no more than 3 authors. They should not exceed 400 words of text and 5 references. Letters reporting original research should not exceed 600 words and 6 references. They may have no more than 5 authors. All letters should include a word count. Letters must not duplicate other material published or submitted for publication. Letters will be published at the discretion of the editors and are subject to editing and abridgment. A signed statement for authorship criteria and responsibility, financial disclosure, copyright transfer, and acknowledgment is required for publication. Letters not meeting these specifications are generally not considered. Before submitting a Research Letter, please review the Instructions for Authors (http://jama.com/instructions). Letters should be submitted via the JAMA online submission and review system at http:// manuscripts.jama.com (note: do not include "www" before the URL). For technical assistance, please contact jama-letters@jama-archives.org.

Letters Section Editor: Robert M. Golub, MD, Senior Editor.

(Reprinted) JAMA, December 8, 2010—Vol 304, No. $22 \mathbf{2 4 8 1}$ 
One possible explanation for the difference in findings is the effect of confounding factors. In the study by Åsvold et al, ${ }^{5}$ a modest attenuation of the association of TSH level with CHD mortality was observed after adjustment for blood pressure and serum lipids, suggesting that the effect of TSH may be at least partially mediated by these factors. Further analysis should be conducted with a similar strategy in the study by Rodondi et al, aimed at those within the reference range of TSH.

\author{
Noboru Takamura, MD, PhD \\ takamura@nagasaki-u.ac.jp \\ Naomi Hayashida, MD, PhD \\ Department of Radiation Epidemiology \\ Takahiro Maeda, MD, PhD \\ Department of Island and Community Medicine \\ Nagasaki University Graduate School of Biomedical Sciences \\ Nagasaki, Japan
}

Financial Disclosures: None reported.

1. Rodondi N, den Elzen WP, Bauer DC, et al; Thyroid Studies Collaboration. Subclinical hypothyroidism and the risk of coronary heart disease and mortality. JAMA 2010;304(12):1365-1374.

2. Knudsen N, Laurberg P, Rasmussen LB, et al. Small differences in thyroid function may be important for body mass index and the occurrence of obesity in the population. J Clin Endocrinol Metab. 2005;90(7):4019-4024.

3. Fernández-Real JM, López-Bermejo A, Castro A, Casamitjana R, Ricart W. Thyroid function is intrinsically linked to insulin sensitivity and endotheliumdependent vasodilation in healthy euthyroid subjects. J Clin Endocrinol Metab. 2006;91(9):3337-3343.

4. Takamura N, Akilzhanova A, Hayashida N, et al. Thyroid function is associated with carotid intima-media thickness in euthyroid subjects. Atherosclerosis. 2009 204(2):e77-e81.

5. Åsvold BO, Bjøro T, Nilsen TI, Gunnell D, Vatten LJ. Thyrotropin levels and risk of fatal coronary heart disease: the HUNT study. Arch Intern Med. 2008;168 (8):855-860.

In Reply: We agree with Dr Rotondi and colleagues and Dr Takamura and colleagues that the mediating factors between subclinical hypothyroidism and CHD remain to be determined, since in our study the associations between subclinical hypothyroidism and CHD remained of similar magnitude after adjustment for traditional cardiovascular risk factors. Rotondi et al hypothesized that inclusion of obese individuals might explain the lack of the significant association with CHD among adults with minimal TSH elevations. We disagree with this hypothesis for several reasons.

First, TSH level in most obese individuals is usually in the normal or upper normal range (2.5-4.5 mIU/L), ${ }^{1}$ even in severe obesity, ${ }^{2}$ so misclassification should be uncommon. Second, further adjustment for BMI (available in 10 of the 11 cohort studies) yielded similar risk estimates, as shown in Table 3 of our article. Third, we have performed a further sensitivity analysis excluding obese participants with a BMI of 30 or more (calculated as weight in kilograms divided by height in meters squared) and found similar results: the age and sex-adjusted HR for CHD events was 1.04 for a TSH level of 4.5 to $6.9 \mathrm{mIU} / \mathrm{L}$ (95\% CI, 0.911.20), 1.18 for a TSH level of 7.0 to $9.9 \mathrm{mIU} / \mathrm{L}$ ( $95 \%$ CI, 0.93 1.49), and 1.95 for a TSH level of $10 \mathrm{mIU} / \mathrm{L}$ or more $(95 \%$ CI, 1.27-2.99; $P=.002$ for trend), with corresponding HRs

2482 JAMA, December 8, 2010—Vol 304, No. 22 (Reprinted) for CHD mortality of 1.07 (95\% CI, 0.87-1.32), 1.45 (95\% CI, 1.04-2.03), and 1.78 (95\% CI, 1.21-2.62; $P=.001$ for trend), respectively. However, as mentioned in our limitations, some participants might have had spontaneous resolution of subclinical hypothyroidism (normalization of TSH without treatment), which might be particularly common in participants with TSH levels of 4.5 to $6.9 \mathrm{mIU} / \mathrm{L}$. Further studies among adults with persistent subclinical hypothyroidism are needed.

Regarding the lack of data on thyroid autoantibodies, the commonly accepted definition of subclinical hypothyroidism $^{3,4}$ is a serum TSH concentration above the statistically defined upper limit of the reference range with normal serum free T4 concentration and does not include thyroid autoantibodies. Differences in risks of subclinical hypothyroidism with and without thyroid autoantibodies should be examined in future studies.

We agree with Takamura et al that the issue of CHD risks related to TSH within the euthyroid range is very interesting, but this question was outside the scope of this specific study.

Nicolas Rodondi, MD, MAS

nicolas.rodondi@hospvd.ch

Department of Ambulatory Care and Community Medicine

University of Lausanne

Lausanne, Switzerland

Douglas C. Bauer, MD

Department of Medicine, Epidemiology and Biostatistics

University of California, San Francisco

Jacobijn Gussekloo, MD, PhD

Department of Public Health and Primary Care

Leiden University Medical Center

Leiden, the Netherlands

Financial Disclosures: None reported.

1. Marzullo $P$, Minocci A, Tagliaferri MA, et al. Investigations of thyroid hormones and antibodies in obesity: leptin levels are associated with thyroid autoimmunity independent of bioanthropometric, hormonal, and weight-related determinants. J Clin Endocrinol Metab. 2010;95(8):3965-3972.

2. Nannipieri $M$, Cecchetti $F$, Anselmino $M$, et al. Expression of thyrotropin and thyroid hormone receptors in adipose tissue of patients with morbid obesity and/or type 2 diabetes: effects of weight loss. Int J Obes (Lond). 2009;33(9):10011006.

3. Surks MI, Ortiz E, Daniels GH, et al. Subclinical thyroid disease: scientific review and guidelines for diagnosis and management. JAMA. 2004;291(2):228238.

4. Helfand $M$; US Preventive Services Task Force. Screening for subclinical thyroid dysfunction in nonpregnant adults: a summary of the evidence for the US Preventive Services Task Force. Ann Intern Med. 2004;140(2):128-141.

\section{Well-being of Patients With Dementia and Their Caregivers After a Biobehavioral Home-Based Intervention}

To the Editor: Dr Gitlin and colleagues ${ }^{1}$ reported the results of the Care of Persons with Dementia in their Environments (COPE) randomized controlled trial, assessing a biobehavioral home-based intervention to support physical function and quality of life for patients with dementia and the well-being of their caregivers. The authors 